\title{
Persepsi Mahasiswa Terhadap Penggunaan Software Geogebra Sebagai Multimedia Pembelajaran Matakuliah Kalkulus Multivariabel
}

\author{
Nurul Arfinanti \\ Program Studi Pendidikan matematika FST UIN Sunan Kalijaga \\ Jl. Marsda Adisucipto, Yogyakarta, Indonesia \\ E-mail:nurularfi@gmail.com
}

\begin{abstract}
This study aims to determine students' perceptions of the use of multimedia learning software GeoGebra in Multivariable Calculus course. Students' perceptions of the use of media or multimedia learning are closely related to their achievement. Media or multimedia learning in accordance with the desire of students will make them motivated. This research is qualitative data analysis was done descriptively. The data obtained in this study comes from researchers as the main instrument, the data questionnaire and interview data is unstructured. The results are students' perceptions of the use of multimedia learning software GeoGebra in Multivariable Calculus courses are in the positive category.
\end{abstract}

Keywords: Studenst Perceptions, GeoGebra, Multivariable Calculus.

\section{Abstrak}

Penelitian ini bertujuan untuk mengetahui persepsi mahasiswa terhadap penggunaan software GeoGebra sebagai multimedia pembelajaran matakuliah Kalkulus Multivariabel. Persepsi mahasiswa terhadap penggunaan media atau multimedia pembelajaran erat kaitannya dengan prestasi belajar mahasiswa. Media atau multimedia pembelajaran yang sesuai dengan keinginan mahasiswa akan membuat mereka termotivasi dalam belajar. Penelitian ini merupakan penelitian kualitatif yang analisis datanya dilakukan secara deskriptif. Data yang diperoleh dalam penelitian ini berasal dari peneliti sebagai instrumen utama, data hasil angket dan juga data hasil wawancara tidak terstruktur. Hasil dari penelitian ini adalah persepsi mahasiswa terhadap penggunaan software GeoGebra sebagai multimedia pembelajaran matakuliah Kalkulus Multivariabel berada pada kategori positif.

Kata Kunci: Persepsi Mahasiswa, Software GeoGebra, Kalkulus Multivariabel 


\section{Pendahuluan}

Teknologi yang berkembang begitu pesat sangat berpengaruh terhadap dunia pendidikan. Perkembangan ini memberikan kesempatan bagi para pendidik untuk senantiasa mengembangakan pembelajarannya dikelas dengan memanfaatkan perkembangan teknologi yang ada. Saat ini telah tersedia berbagai macam teknologi seperti software komputer yang dapat digunakan untuk menunjang kegiatan pembelajaran, termasuk untuk menunjang kegiatan pembelajaran matematika khususnya. Salah satu software komputer yang dapat dimanfaatkan untuk pembelajaran matematika adalah GeoGebra. Software ini dapat digunakan untuk membuat media pembelajaran matematika.

GeoGebra adalah software gratis yang dikembangkan oleh Markus Hohenwarter sejak tahun 2001. Software ini dapat diunduh di http://www.geogebra.org/. Software ini telah diterjemahkan ke dalam banyak bahasa, termasuk Indonesia. Program GeoGebra sangat bermanfaat bagi guru maupun siswa ${ }^{1}$. Tidak sebagaimana pada penggunaan software komersial yang biasanya hanya bisa dimanfaatkan di sekolah, Geogebra dapat diinstal pada komputer pribadi dan dimanfaatkan kapan dan di manapun oleh siswa maupun guru. Bagi guru, GeoGebra menawarkan kesempatan yang efektif untuk 3 mengkreasi lingkungan belajar online interaktif yang memungkinkan siswa mengeksplorasi berbagai konsepkonsep matematis. Lebih lanjut dikatakan bahwa program GeoGebra dapat dimanfaatkan sebagai media pembelajaran matematika ${ }^{2}$. Berikut adalah beberapa pemanfaatan program GeoGebra dalam pembelajaran matematika: (a) dapat menghasilkan lukisan-lukisan geometri dengan cepat dan teliti dibandingkan dengan menggunakan pensil, penggaris, atau jangka, (b) adanya fasilitas animasi dan gerakan-gerakan manipulasi (dragging) pada program GeoGebra dapat memberikan pengalaman visual yang lebih jelas kepada siswa dalam memahami konsep geometri, (c) dapat dimanfaatkan sebagai balikan/evaluasi untuk memastikan bahwa lukisan yang telah dibuat benar, (d) mempermudah guru/siswa untuk menyelidiki atau menunjukkan sifat-sifat yang berlaku pada suatu objek geometri.

${ }^{1}$ Markus Hohenwarter et al., 'Teaching and Learning Calculus with Free Dynamic Mathematics Software Geogebra', in 11th International Congress on Mathematical Education (11th International Congress on Mathematical Education, Mexico: Monterey, 2008), 1-9, https://archive.geogebra.org/static/publications/2008-ICME-TSG16-Calculus-GeoGebraPaper.pdf.

2 Ali Mahmudi, 'Pemanfaatan Geogebra Dalam Pembelajaran Matematika' (Seminar Nasional LPM UNY, Jogjakarta: UNY Jogjakarta, 2011), 1-10, http://staff.uny.ac.id/sites/default/files/Makalah\%2017\%20Semnas\%20LPM\%20UNY\%20 2011\%20_Pemanfaatan\%20GeoGebra\%20dalam\%20Pembelajaran\%20Matematika_pdf. 
Kalkulus Multivariabel merupakan salah satu matakuliah wajib yang mengkaji tentang ruang dimensi tiga, turunan fungsi $n$ variabel, dan integral lipat. Di dalam matakuliah tersebut banyak ditemui fungsi-fungsi dua variabel yang sulit dan tidak mungkin digambar oleh mahasiswa. GeoGebra versi terbaru sudah dapat digunakan untuk menggambar grafik fungsi tiga dimensi. Dengan demikian kita dapat menggunakan software GeoGebra sebagai multimedia dalam pembelajaran matakuliah Kalkulus Multivariabel. Penggunaan software GeoGebra sebagai multimedia pembelajaran matakuliah Kalkulus Multivariabel dapat memberikan visualisasi lebih jelas dibandingkan ketika peneliti menggambar langsung secara manual.

Penggunaan multimedia pembelajaran seharusnya memberikan dampak yang positif bagi prestasi belajar siswa atau mahasiswa. Begitu pula dengan penggunaan software GeoGebra sebagai multimedia pembelajaran matakuliah Kalkulus Multivariabel seharusnya dapat memberikan dampak positif bagi prestasi belajar mahasiswa. Penggunaan media atau multimedia pembelajaran yang tidak sesuai dengan keinginan siswa atau mahasiswa dapat mengakibatkan siswa atau mahasiswa kurang tertarik untuk belajar, sehingga siswa atau mahasiswa tersebut tidak dapat mencapai prestasi belajar yang diinginkan baik dalam proses maupun hasil belajar ${ }^{3}$. Sehingga persepsi siswa atau mahasiswa terhadap penggunaan media atau multimedia sangat penting untuk memastikan bahwa pembelajaran Kalkulus Multivariabel sesuai dengan keinginan mahasiswa.

Setiap mahasiswa pasti memiliki pemikiran masing-masing tentang mengapa mereka menyukai atau membenci suatu matakuliah tertentu. Pemikiran atau kesan yang diperoleh individu melalui panca indera kemudian dianalisa (diorganisir), diintepretasi dan kemudian dievaluasi sehingga individu tersebut memperoleh makna setelah mereka menerima rangsangan berupa proses pembelajaran merupakan suatu persepsi. Persepsi tersebut sangat penting untuk menciptakan lingkungan belajar yang kondusif dan dapat mencapai tujuan pembelajaran. Persepsi positif dari mahasiswa terhadap proses pembelajaran yang berlangsung akan berdampak positif pula terhadap pencapaian hasil belajarnya. Kepuasan merupakan fungsi persepsi atau kesan atas kinerja dan harapan ${ }^{4}$. Jika kinerja (cara pembelajaran oleh dosen/guru) di bawah harapan, maka pelanggan (mahasiswa) tidak puas. Jika kinerja memenuhi harapan, maka pelanggan

${ }^{3}$ Nadu Azizah Islami, 'Pengaruh Persepsi Siswa Mengenai Media Pembelajaran Guru Dan Keaktifan Siswa Dalam Proses Pembelajaran Terhadap Prestasi Belajar' (Universitas Muhammadiyah Surakarta, 2009).

${ }^{4}$ Chairunnisa, 'Persepsi Siswa Terhadap Metode Pembelajaran Guru Dan Hasil Belajar Bahasa Indonesia Di Smk Al-Hidayah Ciputat' (UIN Syarif Hidayatullah Jakarta, 2011). 
(mahasiswa) akan puas. Jika kinerja melebihi harapan, maka pelanggan (mahasiswa) akan amat puas atau senang.

Adanya pengaruh positif antara persepsi siswa tentang media pembelajaran terhadap hasil belajarnya telah dibuktikan oleh Achmad Riady dan Shindy Ekawati. Mereka menemukan bahwa ada pengaruh pada aktivitas dan motivasi belajar siswa yang pada akhirnya berpengaruh positif bagi hasil belajar siswa ${ }^{5}$. Di sisi lain penelitian yang dilakukan oleh Ahmad ibn Abd alRahman al-Samiraa'I, sebagaimana dikutip Nunu Mahnun, ditemukan bahwa tingkat pencapaian pengetahuan melalui indera penglihatan mencapai 75\%, sementara melalui indera pendengaran hanya 13\%, sedangkan melalui indera lain, seperti pengecapan, sentuhan, penciuman, pengetahuan hanya dapat diperoleh sebesar 12\%. Lingkungan belajar yang dilengkapi dengan gambar-gambar memberikan dampak 3 kali lebih kuat dan mendalam daripada kata-kata (ceramah). Sementara jika gambar dan kata-kata dipadukan, maka dampaknya lebih kuat daripada kata-kata saja. Karena itu media pembelajaran yang dapat memadukan kata-kata (suara) dan gambar diyakini dan terbukti memberikan peran penting dalam menunjang efektifitas pembelajaran yang dilakukan oleh guru. Dengan penggunaan software GeoGebra sebagai multimedia pembelajaran matakuliah Kalkulus Multivariabel, maka dapat ditampilkan gambar-gambar dan berbagai macam ilustrasi yang dapat membantu siswa atau mahasiswa mencapai pemahaman konsep ${ }^{6}$.

Berdasarkan latar belakang di atas, penulis tertarik untuk mengetahui persepsi mahasiswa terhadap penggunaan software GeoGebra sebagai multimedia pembelajaran Kalkulus Multivariabel. Adapun rumusan masalah dalam penelitian ini adalah bagaimana persepsi mahasiswa terhadap penggunaan software GeoGebra sebagai multimedia pembelajaran Kalkulus Multivariabel.

${ }^{5}$ Achmad Riady and Shindy Ekawati, 'Pengaruh Persepsi Siswa Pada Multimedia Pembelajaran Terhadap Aktivitas Dan Motivasi Yang Berimplikasi Terhadap Hasil Belajar Siswa', Jurnal Pedidikan Matematika Pedagogy 1, no. 1 (2016).

${ }^{6}$ Nunu Mahnun, 'Media Pembelajaran (Kajian Terhadap Langkah-Langkah Pemilihan Media Dan Implementasinya Dalam Pembelajaran)', Jurnal Pemikiran Islam 37, no. 1 (2012). 


\section{Metode Penelitian}

Dalam penelitian ini, peneliti melakukan analisis persepsi mahasiswa terhadap penggunaan software GeoGebra sebagai multimedia pembelajaran matakuliah Kalkulus Multivariabel. Dalam penelitian ini peneliti merupakan instrumen utama. Peneliti menggunakan angket dan wawancara tidak terstruktur sebagai instrumen pengumpulan data. Selain itu peneliti juga mendokumentasikan kegiatan pembelajaran matakuliah kalkulus lanjut dengan menggunakan software GeoGebra sebagai multimedia pembelajarannya. Tujuan dari penelitian ini adalah untuk mendeskripsikan persepsi mahasiswa terhadap penggunaan software GeoGebra sebagai multimedia pembelajaran matakuliah Kalkulus Multivariabel.

Berdasarkan hal tersebut di atas, apa yang dilakukan oleh peneliti merupakan penelitian kualitatif. Penelitian kualitatif adalah penelitian yang bermaksud untuk memahami fenomena tentang apa yang dialami oleh subjek penelitian misalnya perilaku, persepsi, motivasi, tindakan, dll., secara holistik, dan dengan cara deskripsi dalam bentuk kata-kata dan bahasa, pada suatu konteks khusus yang alamiah dan dengan memanfaatkan berbagai metode alamiah ${ }^{7}$.

Subjek penelitian ini adalah mahasiswa yang mengambil matakuliah Kalkulus Multivariabel pada Program Studi Pendidikan Matematika Fakultas Sains dan Teknologi UIN Sunan Kalijaga semester gasal tahun akademik 2016/2017.

Agar menghasilkan data yang valid, maka dalam penelitian ini dilakukan teknik triangulasi data. Triangulasi data dalam penelitian ini meliputi data hasil observasi yang dilakukan oleh peneliti sebagai instrumen utama, data hasil angket yang telah dideskripsikan, serta data hasil wawancara tidak terstruktur.

Analisis data yang dilakukan dalam penelitian ini adalah analisis data secara deskriptif untuk data yang dihasilkan dari peneliti sebagai instrumen utama dan juga untuk data hasil wawancara tidak terstruktur. Untuk data hasil angket, data yang dihasilkan berupa data kuantitatif sehingga data tersebut perlu dikonversi ke bentuk kualitatif. Berikut adalah tahap-tahap pengeolahan data hasil angket persepsi mahasiswa:

1. Memberikan skor berdasarkan skala Likert. Pernyataan yang digunakan dalam skala Likert untuk mengetahui persepsi mahasiswa adalah pernyataan positif dan negatif. Pilihan jawaban mahasiswa dikategorikan

${ }^{7}$ Lexy J Moleong, Metodologi Penelitian Kualitatif (Bandung: PT. Remaja Rosdakarya Offset, 2006), 6. 
Sangat Setuju (SS), Setuju (S), Tidak Setuju (TS), dan Sangat Tidak Setuju (STS). Cara pemberian skor angket dapat dilihat pada Tabel 1 berikut $^{8}$ :

Tabel 1. Cara Pemberian Skor Angket

\begin{tabular}{|c|c|c|c|c|}
\hline \multirow{2}{*}{ Pernyataan } & \multicolumn{4}{|c|}{ Skor } \\
\cline { 2 - 5 } & SS & S & TS & STS \\
\hline Positif & 4 & 3 & 2 & 1 \\
\hline Negatif & 1 & 2 & 3 & 4 \\
\hline
\end{tabular}

2. Mengolah skor angket persepsi berdasarkan tahapan: (a) menentukan skor minimal, skor maksimal, nilai median (hasil penjumlahan skor maksimal dengan skor maksimal dibagi dua), nilai kuartil 1 (hasil penjumlahan skor minimal dengan median dibagi dua), nilai kuartil 3 (hasil penjumlahan skor maksimal dengan median dibagi dua); (b) membuat skala yang menggambarkan skor minimal, nilai kuartil 1, nilai median, nilai kuartil 3, dan skor maksimal; (c) mencari batas-batas skor untuk masing-masing kategori; (d) membuat tabel distribusi frekuensi untuk persepsi mahasiswa terhadap penggunaan software GeoGebra sebagai multimedia pembelajaran matakuliah Kalkulus Multivariabel ${ }^{9}$. Tabel distribusi frekuensi persepsi mahasiswa dapat dilihat pada Tabel 2 berikut:

Tabel 2. Distribusi Frekuensi Persepsi Mahasiswa

\begin{tabular}{|l|l|}
\hline \multicolumn{1}{|c|}{ Kategori Persepsi } & \multicolumn{1}{c|}{ Kategori Skor } \\
\hline Persepsi Sangat Positif & Kuartil $3<\bar{x} \leq$ Skor maksimal \\
\hline Persepsi Positif & Skor median $<\bar{x} \leq$ kuartil 3 \\
\hline Persepsi Negatif & Kuartil $1<\bar{x} \leq$ Skor median \\
\hline Persepsi Sangat negatif & Skor minimal $\leq \bar{x} \leq$ Kuartil 1 \\
\hline
\end{tabular}

\footnotetext{
${ }^{8}$ Sukardi, Metodologi Penelitian Pendidikan (Jakarta: Bumi Aksara, 2004), 147.

${ }^{9}$ Zaenal Arifin, Evaluasi Pembelajaran: Prinsip, Teknik, Dan Prosedur (Jakarta: Bumi Aksara, 2009), 233.
} 


\section{Aktivitas Matakuliah Kalkulus Multivariabel}

Persepsi mahasiswa terhadap penggunaan software GeoGebra sebagai multimedia pembelajaran matakuliah Kalkulus Multivariabel sangat beragam. Awalnya mereka belum begitu tertarik dengan matakuliah Kalkulus Multivariabel dikarenakan mereka sudah memiliki persepsi yang negatif terhadap matakuliah ini. Sebelum perkuliahan dimulai, beberapa mahasiswa diberi pertanyaan awal tentang apa yang mereka ketahui tentang matakuliah Kalkulus Multivariabel. Sebagian besar dari mereka menjawab bahwa matakuliah Kalkulus Multivariabel adalah matakuliah yang sulit dan tidak menyenangkan. Dalam persepsi mereka matakuliah ini seperti momok yang menakutkan. Asusmsi mereka tersebut dilatarbelakangi dari matakuliahmatakuliah yang menjadi prasyarat bagi matakuliah ini yaitu kalkulus differensial dan kalkulus integral yang memang bagi sebagaian besar mahasiswa bukan merupakan matakuliah yang mudah.

Meskipun demikian, sebagaian besar mahasiswa menunjukkan antusiasme ketika mengikuti perkuliahan. Ketika ditanya tentang apakah mereka sudah mengenal dan menggunakan software GeoGebra, sebagian besar mahasiswa hanya pernah mendengar tetapi belum pernah mencoba sendiri.

Pada pertemuan awal matakuliah Kalkulus Multivariabel dibahas tentang fungsi dua variabel dan bagaimana grafiknya. Software GeoGebra kemudian digunakan untuk membantu menggambar grafik fungsi yang dimaskud. Berikut adalah contoh penggunaan software GeoGebra untuk menggambar grafik fungsi dua variabel.

Mahasiswa diminta untuk menentukan daerah asal alami (domain) dan daerah hasil (range) fungsi $\mathrm{f}(\mathrm{x}, \mathrm{y})=\sqrt{36-\mathrm{x}^{2}-\mathrm{y}^{2}}$. Pada awalnya mahasiswa terlihat bingung, bagaimana harus mencari domain dan range dari fungsi tersebut. Dari raut wajah mereka terlihat banyak yang menganggap soal tersebut sangat sulit. Hal ini didukung saat peneliti bertanya bagaimana mencari domain dan range dari fungsi tersebut. Ada mahasiswa yang mengatakan bahwa mencari domain dan range dari fungsi satu variabel saja sulit, apalagi untuk fungsi dua variabel. Peneliti kemudian menggambar grafik fungsi tersebut dengan bantuan software GeoGebra. Gambar yang dihasilkan dengan menggunakan software GeoGebra merupakan gambar setengah bola. Gambar grafik juga dapat diputar sehingga memberikan gambaran yang lebih jelas tentang grafik fungsi dua variabel yang dimaksud. Mahasiswa terlihat memperhatikan dengan seksama gambar grafik yang dihasilkan. Contoh gambar yang dihasilkan dengan menggunakan software GeoGebra dapat dilihat pada Gambar 1 berikut: 


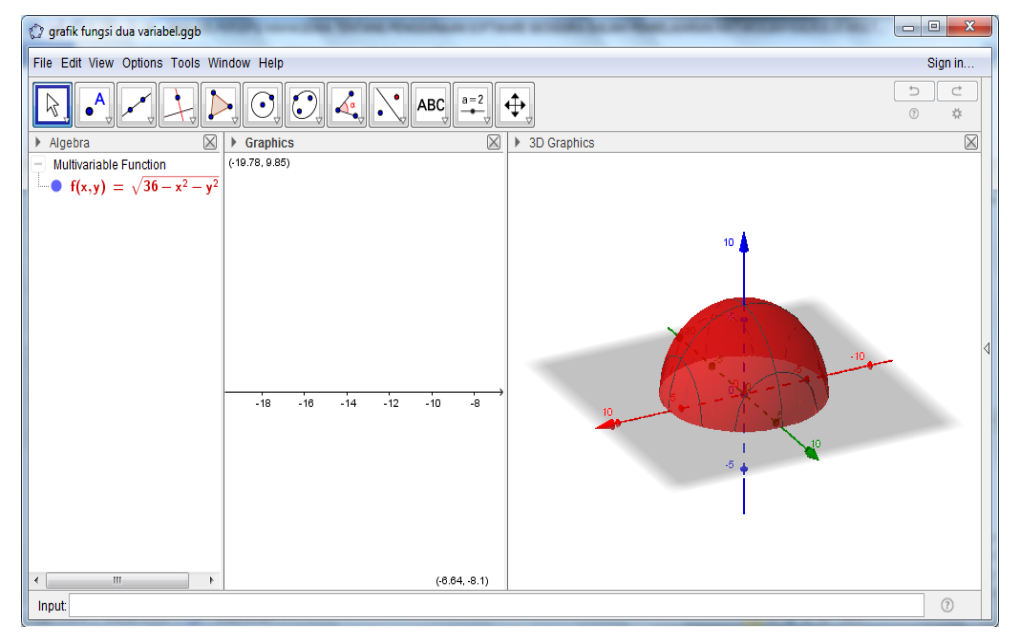

Gambar 1. Contoh Gambar Grafik Fungsi Dua Variabel Dengan Software GeoGebra

Berdasarkan Gambar 1 tersebut, mahasiswa kemudian diminta untuk menunjukkan di mana daerah asal yang dimaksud. Sebelumnya peneliti terlebih dahulu mengingatkan tentang pengertian domain dan range pada fungsi satu variabel. Terlihat beberapa mahasiswa mengacungkan tangan berusaha untuk menjawab pertanyaan. Mereka menyebutkan bahwa domainnya adalah bidang $x y$. Meskipun belum menjawab dengan tepat, tetapi mereka sudah memiliki bayangan bahwa daerah asal berada pada bidang $x y$. Peneliti kemudian memberikan bantuan agar mahasiswa dapat memperoleh jawaban dari pertanyaan yang diberikan. Peneliti kemudian bertanya, "Apakah syarat agar fungsi tersebut terdefinisi?". Ada mahasiswa yang tersenyum dan kemudian mengacungkan tangan dan menjawab, "Yang di dalam akar tidak boleh negatif $\mathrm{Bu}$, atau harus lebih besar sama dengan nol." Mahasiswa kemudian diminta untuk mencermati kembali gambar grafik fungsinya dan menunjukkan daerah asal dan daerah hasil dari fungsi yang dimaksud. Mahasiswa kemudian mengatakan bahwa daerah asalnya adalah daerah lingkaran (titik-titik di dalam dan pada lingkaran) dengan jari-jari 6 dan berpusat di $(0,0)$. Mereka menjawab demikian setelah melihat gambar grafik fungsinya. Peneliti kemudian bertanya tentang daerah hasil dari fungsi yang diberikan dengan mencermati gambar grafik fungsi. Mahasiswa kemudian menjawab daerahnya adalah $\{0 \leq \mathrm{z} \leq 6\}$. Setelah mendengar jawaban dari mahasiswa peneliti kemudian meminta mahasiswa menghitung dengan cara analitis apakah menghasilkan daerah asal dan daerah hasil yang sesuai atau tidak. 
Berdasarkan paparan data di atas, terlihat bahwa penggunaan software GeoGebra sebagai multimedia pembelajaran dapat membantu mahasiswa siswa memahami konsep. Hal ini sesuai dengan pendapat Ibrahim dan Suparni yang mengatakan bahwa salah satu nilai praktis dari penggunaan media dalam proses pembelajaran adalah dapat memberikan pengalaman yang integral dari suatu yang kongkrit sampai kepada yang abstrak ${ }^{10}$. Selain itu penggunaan media pembelajaran juga dapat membangkitkan motivasi dan merangsang siswa belajar. Hal ini terlihat dari aktivitas mahasiswa yang begitu memperhatikan penjelasan dosen pada saat menggunakan software GeoGebra sebagai multimedia pembelajaran.

\section{Deskripsi Hasil Wawancara dan Angket Mahasiswa tentang Penggunaan GeoGebra}

Menurut hasil wawancara dengan mahasiswa, mereka mengatakan bahwa penggunaan software GeoGebra dapat membantu mereka untuk dapat membayangkan daerah asal maupun daerah hasil dari fungsi dua variabel. Mereka memiliki persepsi yang baik terhadap penggunaan software GeoGebra dalam pembelajaran matakuliah Kalkulus Multivariabel. Persepsi positif terhadap penggunaan software GeoGebra juga ditunjukkan oleh mahasiswa ketika mempelajari tentang peta kontur. Gambar 2 berikut adalah salah satu penggunaan software GeoGebra dalam menggambarkan peta kontur.

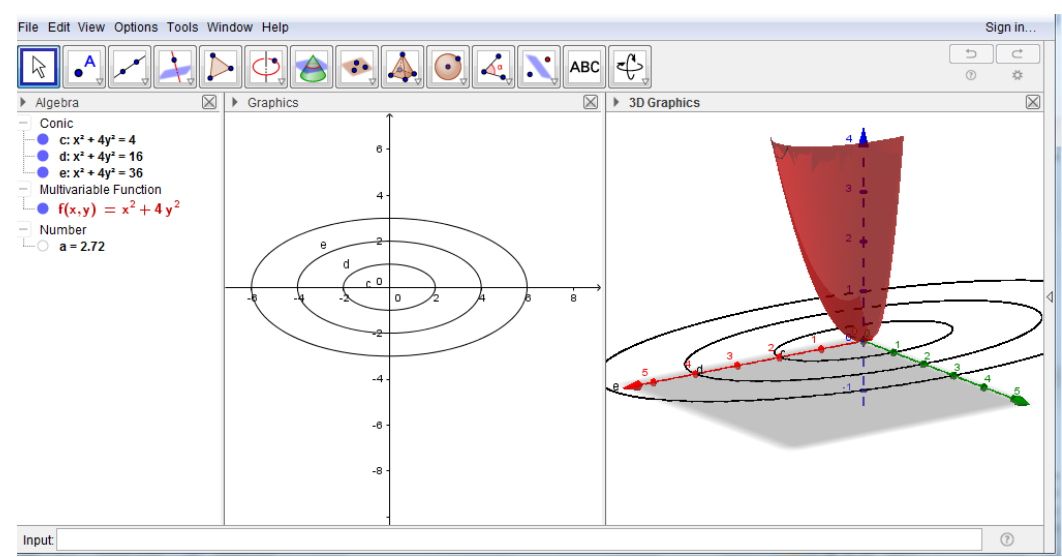

Gambar 2. Contoh Penggunaan Software GeoGebra pada Peta Kontur

${ }^{10}$ Ibrahim and Suparni, Strategi Pembelajaran Matematika (Yogyakarta: UIN Sunan Kalijaga, 2008), 117. 
Hasil penentuan skor minimal, kuartil 1, nilai median, kuartil 3, dan nilai maksimal dapat dilihat pada Tabel 3 berikut:

Tabel 3. Skor Minimal, Kuartil 1, Nilai Median, Kuartil 3, Dan Nilai Maksimal

\begin{tabular}{|c|c|}
\hline Skor Minimal & 10 \\
\hline Kuartil 1 & 17,5 \\
\hline Median & 25 \\
\hline Kuartil 3 & 32,5 \\
\hline Skor Maksimal & 40 \\
\hline
\end{tabular}

Hasil akhir pengolahan data persepsi mahasiswa terhadap penggunaan software GeoGebra sebagai multimedia pembelajaran matakuliah Kalkulus Multivariabel dapat dilihat pada Tabel 4 berikut:

Tabel 4. Distribusi Frekuensi Persepsi Mahasiswa

\begin{tabular}{|c|c|}
\hline Kategori Persepsi & Kategori Skor \\
\hline Persepsi Sangat Positif & $32,5<\bar{x} \leq 40$ \\
\hline Persepsi Positif & $25<\bar{x} \leq 32,5$ \\
\hline Persepsi Negatif & $17,5<\bar{x} \leq 25$ \\
\hline Persepsi Sangat negatif & $10 \leq \bar{x} \leq 17,5$ \\
\hline
\end{tabular}

Hasil analisis data angket persepsi mahasiswa diperoleh nilai rata-rata hasil angket persepsi mahasiswa sebesar 30,13. Hal ini berarti persepsi mahasiswa terhadap penggunaan software GeoGebra sebagai multimedia pembelajaran matakuliah Kalkulus Multivariabel berada pada kategori positif.

Secara umum berikut adalah persepsi mahasiswa terhadap penggunaan software GeoGebra sebagai multimedia pembelajaran matakuliah Kalkulus Multivariabel.

1. Sebagian besar mahasiswa memiliki persepsi bahwa penggunaan Software Geogebra pada matakuliah Kalkulus Multivariabel dapat membantu mahasiswa dalam belajar. Hal ini ditunjukkan dengan meningkatnya pemahaman mahasiswa terhadap materi yang diberikan. Ketika diberikan pertanyaan, mahasiswa sudah dapat memberikan penjelasan tentang jawaban mereka dengan benar. Selain itu, hal ini juga ditunjukkan dengan hasil angket untuk pernyataan pada point tersebut memiliki rata-rata skor 3,4 dari skala 4. Artinya kebanyakan mahasiswa setuju bahwa pembelajaran matakuliah Kalkulus Multivariabel dengan menggunakan software GeoGebra dapat membantu mahasiswa dalam belajar. 
2. Sebagaian besar mahasiswa memiliki persepsi bahwa penggunaan software GeoGebra dapat menarik minat mereka untuk belajar khusunya pada matakuliah Kalkulus Multivariabel. Hal ini terlihat dari antusiasme mereka saat kegiatan perkuliahan berlangsung. Mereka terlihat memperhatikan dengan seksama penjelasan dari peneliti.

3. Sebagaian besar mahasiswa memiliki persepsi bahwa penggunaan software GeoGebra dapat membantu mereka dalam memahami materi yang diajarkan.

4. Sebagaian besar mahasiswa memiliki persepsi bahwa penggunaan software GeoGebra dapat membantu mahasiswa dalam menggambar grafik fungsi tiga dimensi atau grafik fungsi dua variabel.

Sebagaian besar mahasiswa memiliki persepsi bahwa penggunaan software GeoGebra dapat digunakan dengan mudah oleh mahasiswa dan dapat dipelajari secara mandiri. Meskipun demikian, hanya sebagian kecil dari mahasiswa yang mempelajari kembali secara mandiri materi perkuliahan Kalkulus Multivariabel dengan menggunakan software GeoGebra. Ketika ditanya alasannya, mereka mengatakan tidak memiliki waktu yang cukup karena banyak tugas kuliah yang harus mereka selesaikan.

\section{Penutup}

Berdasarkan hasil penelitian dan pembahasan di atas dapat disimpulkan bahwa mahasiswa memiliki persepsi yang positif terhadap penggunaan software GeoGebra sebagai multimedia pembelajaran matakuliah Kalkulus Multivariabel. Sebagaian besar mahasiswa memiliki persepsi bahwa penggunaan software Geogebra pada matakuliah Kalkulus Multivariabel dapat: (a) membantu mahasiswa dalam belajar, (b) menarik minat mereka untuk belajar khusunya pada matakuliah Kalkulus Multivariabel, (c) membantu mereka dalam memahami materi yang diajarkan, (d) membantu mahasiswa dalam menggambar grafik fungsi tiga dimensi atau grafik fungsi dua variabel, dan (e) digunakan dengan mudah dan dipelajari secara mandiri. Hasil angket persepsi mahasiswa yang memiliki nilai rata-rata 30,13 . Hal ini berarti persepsi mahasiswa terhadap penggunaan software GeoGebra sebagai multimedia pembelajaran matakuliah Kalkulus Multivariabel berada pada kategori positif. 


\section{Daftar Pustaka}

Arifin, Zaenal. Evaluasi Pembelajaran: Prinsip, Teknik, Dan Prosedur. Jakarta: Bumi Aksara, 2009.

Chairunnisa. 'Persepsi Siswa Terhadap Metode Pembelajaran Guru Dan Hasil Belajar Bahasa Indonesia Di Smk Al-Hidayah Ciputat'. UIN Syarif Hidayatullah Jakarta, 2011.

Hohenwarter, Markus, Judith Hohenwarter, Yves Kreis, and Zsolt Lavicza. 'Teaching and Learning Calculus with Free Dynamic Mathematics Software Geogebra'. In 11th International Congress on Mathematical Education, 1-9. Mexico: Monterey, 2008. https://archive.geogebra.org/static/publications/2008-ICME-TSG16Calculus-GeoGebra-Paper.pdf.

Ibrahim, and Suparni. Strategi Pembelajaran Matematika. Yogyakarta: UIN Sunan Kalijaga, 2008.

Islami, Nadu Azizah. 'Pengaruh Persepsi Siswa Mengenai Media Pembelajaran Guru Dan Keaktifan Siswa Dalam Proses Pembelajaran Terhadap Prestasi Belajar'. Universitas Muhammadiyah Surakarta, 2009.

Mahmudi, Ali. 'Pemanfaatan Geogebra Dalam Pembelajaran Matematika', 110. Jogjakarta: UNY Jogjakarta, 2011. http://staff.uny.ac.id/sites/default/files/Makalah\%2017\%20Semnas\% 20LPM\%20UNY\%202011\%20_Pemanfaatan\%20GeoGebra\%20dalam \%20Pembelajaran\%20Matematika_pdf.

Mahnun, Nunu. 'Media Pembelajaran (Kajian Terhadap Langkah-Langkah Pemilihan Media Dan Implementasinya Dalam Pembelajaran)'. Jurnal Pemikiran Islam 37, no. 1 (2012).

Moleong, Lexy J. Metodologi Penelitian Kualitatif. Bandung: PT. Remaja Rosdakarya Offset, 2006.

Riady, Achmad, and Shindy Ekawati. 'Pengaruh Persepsi Siswa Pada Multimedia Pembelajaran Terhadap Aktivitas Dan Motivasi Yang Berimplikasi Terhadap Hasil Belajar Siswa'. Jurnal Pedidikan Matematika Pedagogy1, no. 1 (2016).

Sukardi. Metodologi Penelitian Pendidikan. Jakarta: Bumi Aksara, 2004. 